\title{
The orchard of the future - new technologies
}

\section{Editorial}

Fruit production is a complex of the interaction among soil, plant, and environmental factors, and its correct understanding may lead to two important factors in the sustainability of fruit growing, productivity, and quality. The correlation between fruit productivity and quality is mainly related to the development of technologies, but they are directly or indirectly affected by environmental conditions that may give a differential in a given region. In recent years, the fruit growing has undergone major changes that have led to significant increases in fruit productivity and quality. In addition to these two factors, we cannot forget the technologies that lead to a rationalization of labor with a reduction in manual labor and an increase in mechanization. In apple orchards, the major transformation was to move from low density with 500 to 800 plants per ha to high density with 2,500 to 5,000 plants per ha. To bring about this transformation came other associated technologies such as narrow canopy training systems that allow high mechanization. It is necessary to reevaluate certain cultural practices that demand high labor, leading producers to re-engineer in order to increase its efficiency, which leads to mechanization with the development of machines capable of increasing the efficiency of various management activities in the orchard to make them indispensable as electric and pneumatic pruning scissors, harvest platforms, flail mowers, among others. The changes have been taking place, but it is necessary that they occur in an orderly manner and at a speed compatible with the growth and dynamism of the various production chains.

Several items must be considered before implementing an orchard of the future, always thinking that the orchard implanted today in most of the species of fruit trees will remain for 20 or more years. One of the successes in the establishment of the orchard is in the choice of cultivars, depending on the species, diversity is fundamental, both for its organoleptic qualities, conservation and maturation time. In the case of apple trees, the tendency is for international cultivars, such as those of the group Delicious, Golden in the past, and in recent years the cultivars of the groups Gala and Fuji have grown. Currently, the club varieties have been rapidly evolving, introducing new cultivars and restricting them to a group of growers, controlling the volume of production. New disease-resistant cultivars should facilitate the development of agroecological farming systems with a consequent reduction in the use of pesticides. In the choice of rootstock, many advances are necessary searching for rootstocks that reduce the vigor of the plant, induce early production, resistance to pests and soil diseases, and develop a compact plant that allows maximum mechanization. The plant training systems should be small and twodimensional allowing maximum mechanization and adapt to highdensity systems since the increase in planting density is one of the
Volume 4 Issue 3 - 2020

\author{
José Luiz Petri \\ Engener of Agricuture MSc,Estação Experimental de Caçador, \\ Brazil
}

Correspondence: José Luiz Petri, Engener of Agricuture MSc, Estação Experimental de Caçador, Brazil, Email petri@eagri.sc.gov.br

Received: June 14, 2020 | Published: June 29, 2020

most important factors in increasing productivity that, accompanied by the training system, improve fruit quality. Among the temperate fruit trees, the apple trees have innovated in terms of planting density and training systems. A worldwide trend is planting densities with more than 3,000 plants per hectare with new training systems such as the two-dimensional multi-leader that allows a better exposure of the fruit allowing better coloring.

Technologies such as chemical thinning cannot be dispensed from the different production systems for different fruit trees, allowing better quality of the fruits and maintaining constant yield. Nor can be dispensed the use of plant growth regulators, being important in the management of the orchard, aiming at improving the quality of the fruits and maintaining the regularity of the production, promoting the increase of the caliber of the fruits, improving the fruit set and improving the color of the fruits. Certain practices such as the control of vegetative growth that allows the reduction of pruning labor, the delay in fruit ripening with the staggering of the harvest that allows a better rationalization of labor. In this context, the use of growth regulators is an important tool that cannot be dispensed within the different production systems of temperate fruit trees.

Finally, certification systems that allow traceability and consumer safety, allowing the production of fruits with the guarantee of exemption from chemical residues, cannot be forgotten.

\section{Acknowledgments}

None.

\section{Conflicts of interest}

Authors declare no conflict of interest exists. 